\title{
GERMINAÇÃO DE SEMENTES ARMAZENADAS DE GUANDU ${ }^{1}$
}

\author{
JOÃO NAKAGAWA², CLÁUDIO CAVARIANI ${ }^{3}$, MARIANA ZAMPAR TOLEDO ${ }^{4}$
}

\begin{abstract}
RESUMO - O guandu (Cajanus cajan (L.) Millsp) é uma leguminosa arbustiva utilizada para adubação verde e como forrageira; seus grãos ricos em proteína servem de alimento animal e humano. No presente experimento objetivou-se estudar o comportamento da germinação de sementes de guandu de dois cultivares (um com e outro sem sementes duras) durante o armazenamento. As sementes recém-colhidas foram embaladas em sacos de papel e armazenadas durante seis anos em condições ambientais de laboratório, sem controle de temperatura e umidade relativa do ar. Logo após a colheita e depois anualmente, foi determinado o teor de água das sementes e realizado o teste de germinação. Os dados de germinação foram submetidos à análise estatística, em delineamento inteiramente ao acaso, considerando as sete avaliações durante o armazenamento como tratamentos, com quatro repetições. As análises de variância foram realizadas separadamente para cada cultivar e a seguir feita análise conjunta. Equações de regressão foram calculadas, escolhendo-se aquelas com melhor ajuste e maior coeficiente de determinação $\left(\mathrm{R}^{2}\right)$. As sementes das duas cultivares se mantiveram viáveis durante três anos de armazenamento com germinação acima de $70 \%$, seguido de queda, para no sexto ano estar próxima a $10 \%$. A presença de sementes duras ocasiona diferença na germinação dos cultivares no transcorrer do período de armazenamento.
\end{abstract}

Termos para indexação: Cajanus cajan, armazenamento, viabilidade, deterioração.

\section{GERMINATION OF STORED PIGEON PEA SEEDS}

\begin{abstract}
The pigeon pea (Cajanus cajan (L.) Millsp) is a shrubby leguminous plant cropped for green manure and forage; its protein-rich grains are used as animal and human food. The objective of the present experiment was to study the germination behavior during the storage of pigeon pea seeds of two cultivars (one with and the other without hard seeds). The newly harvested seeds were packed in paper bags and stored for six years in a laboratory with natural environment without control of air temperature and relative humidity. Soon after harvest and then yearly, seed moisture was evaluated and the seed germination was tested. Germination dates were submitted to statistical analysis, in a randomized complete design, considering as treatments the seven evaluation times during storage, with four replications. Analysis of variance was performed for each cultivar separately and then analyzed as series of similar experiments.
\end{abstract}

${ }^{1}$ Submetido em 21/10/2008. Aceito para publicação em 30/06/2009.

${ }^{2}$ Professor titular aposentado, Voluntário, Departamento de Produção Vegetal, Faculdade de Ciências Agronômicas, UNESP, campus de Botucatu, Caixa Postal 237, 18610-307. Botucatu-SP, email: secdamv@fca.unesp.br.

${ }^{3}$ Professor Assistente Doutor, Departamento de Produção Vegetal,
Faculdade de Ciências Agronômicas, UNESP, campus de Botucatu, Caixa Postal 237, 18610-307. Botucatu-SP, email: ccavariani@fca.unesp.br.

${ }^{4}$ Pós graduanda, Departamento de Produção Vegetal, Faculdade de Ciências Agronômicas, UNESP, campus de Botucatu, Caixa Postal 237, 18610-307. Botucatu-SP, email: mztoledo@fca.unesp.br. 
Regression equations were calculated, choosing the ones with better fit and higher coefficient of determination. Seeds of both cultivars maintained germination above $70 \%$ during three years of storage, followed by decrease and presented nearly $10 \%$ in the sixth year. The presence of hard seeds caused differences in germination between cultivars during the storage period.

Index terms: Cajanus cajan, storage, viability, deterioration.

\section{INTRODUÇÃO}

O guandu (Cajanus cajan (L.) Millsp) é uma leguminosa arbustiva, anual ou perene, que foi introduzida no Brasil há muito tempo, tendo-se adaptado perfeitamente às condições do país (Otero, 1952). É cultivado principalmente como adubo verde e em menor escala como forrageira para fornecer alimento para o gado bovino, nos períodos de estiagem (Giomo, 1999). Os grãos são ricos em proteína, podendo ser utilizados tanto na alimentação animal como humana (Calegari, 1995).

Apesar da introdução ser antiga, a cultura não se estabeleceu como de importância econômica, tendo como conseqüência ou causa, os poucos trabalhos de pesquisa com esta espécie, principalmente aos relacionados à produção e qualidade de sementes (Vieira et al., 1986; Pedroso et al., 1988; Giomo, 1999); sendo mais restrito os de armazenamento de sementes, mesmo na literatura internacional (Ellis et al., 1979; Rao et al., 1982; Hepperly e Rodríguez, 1984; Asalmol e Zade, 1998; Godoy e Souza, 2004).

A capacidade de manutenção da viabilidade das sementes de guandu é influenciada pelo teor de água e pelas condições de armazenamento, conservando-se bem quando apresentam teores baixos e sob baixa umidade relativa e temperatura do ambiente, porém o potencial de armazenamento torna-se diferente entre os genótipos (Ellis et al., 1979; Rao et al., 1982; Godoy e Souza, 2004).

A qualidade inicial, fisiológica e sanitária, aliada às características das sementes do genótipo afeta o potencial de conservação das sementes de guandu; os genótipos com sementes pequenas e duras apresentam menor invasão de fungos patogênicos, conservando a viabilidade por maior período (Hepperly e Rodríguez, 1984). A realização do tratamento fungicida antes do armazenamento, seguido de novo tratamento após nove meses, mostrou-se efetivo no controle dos fungos de armazenamento; todavia, as sementes de guandu mesmo sem tratamento, embaladas em sacos de papel e com teor de água menor que 9\%, exibiram boa armazenabilidade, mantendo a germinação nos 27 meses estudados, em condições ambientais (Asalmol e Zade, 1998).

A presença de sementes duras, embora seja característica para garantir a preservação das sementes e da espécie, não é desejável em genótipos comerciais, pois traz inconvenientes na implantação da cultura e por perenizar as populações que as apresentam, tornando-as futuras plantas invasoras da cultura ou pastagem sucessora. Em guandu, embora possa apresentar sementes duras (Brasil, 1992), o percentual presente não costuma ser problema para os cultivares comerciais (Seiffert, 1982).

O objetivo do trabalho foi estudar o comportamento da germinação de sementes de guandu de dois cultivares (um com e outro sem sementes duras) durante o armazenamento em condições ambientais de laboratório sem controle de temperatura e umidade relativa.

\section{MATERIAL E MÉTODOS}

O experimento foi conduzido com sementes de dois cultivares de guandu (Cajanus cajan (L.) Millsp) em condições de laboratório no Departamento de Produção Vegetal/Agricultura, da Faculdade de Ciências Agronômicas do campus de Botucatu, UNESP.

Os cultivares utilizados, aqui denominados cv. A (Fava larga) e cv. B (com sementes de coloração marromavermelhada, apresentando sementes duras), foram cultivados na Fazenda Experimental de São Manoel, pertencente à UNESP, Botucatu. As sementes, logo após trilha manual das vagens colhidas secas e maduras, foram classificadas por peneiras com perfurações oblongas, sendo utilizadas no experimento as retidas na peneira 12/64 x 3/4" (4,76 x 19,05 mm) por representarem maior proporção para os dois cultivares. Essas foram armazenadas em condições de laboratório, sem controle de temperatura e umidade relativa do ambiente, embaladas em sacos de papel unifoliado.

As sementes foram avaliadas quanto ao teor de água e submetidas ao teste de germinação, antes do armazenamento (recém-colhidas) e em intervalos anuais até o sexto ano, 
sempre durante o mês de julho.

$\mathrm{O}$ delineamento experimental utilizado foi $\mathrm{o}$ inteiramente casualizado, considerando-se os sete momentos de avaliação durante o armazenamento como tratamentos, com quatro repetições para os dados avaliados no teste de germinação, em cada cultivar.

$\mathrm{O}$ teor de água foi determinado pelo método da estufa a $105 \pm 3^{\circ} \mathrm{C}$ durante 24 horas, utilizando-se duas repetições de aproximadamente $30 \mathrm{~g}$ cada, seguindo-se os procedimentos das Regras para Análise de Sementes (Brasil, 1992). O teste de germinação foi realizado com quatro repetições de 50 sementes, empregando papel toalha (RP), umedecido com água na quantidade de duas vezes e meia a massa do papel seco; a temperatura do germinador no qual as sementes foram dispostas era de $30^{\circ} \mathrm{C}$ e as contagens realizadas aos 5 e 10 dias após a semeadura (Brasil, 1992). Nas avaliações foram consideradas as plântulas normais da primeira contagem, o total de plântulas normais (germinação), as plântulas anormais, as sementes duras e as sementes mortas, dados expressos em porcentagem.

Os dados obtidos, exceção ao teor de água, foram submetidos à análise de variância, em esquema inteiramente ao acaso, com quatro repetições, separadamente para cada cultivar e a seguir feita análise conjunta, considerando os dois cultivares e os períodos de armazenamento. Os dados em porcentagem foram transformados, antes das análises, em $y=\operatorname{arcsen}(x / 100)^{1 / 2}$ e em $y=(x+0,5)^{1 / 2}$ para primeira contagem e sementes duras por apresentarem dados com valor zero. Ajustes polinomiais até o terceiro grau foram testados e equações de regressão para os dados ajustados foram calculadas, escolhendo-se aquelas com melhor ajuste e maior coeficiente de determinação $\left(\mathrm{R}^{2}\right)$.

\section{RESULTADOS E DISCUSSÃO}

O teor de água das sementes dos dois cultivares foi semelhante durante todo o período de armazenamento, indicando que o equilíbrio higroscópico com o ambiente procedeu-se de forma análoga, com queda paulatina de o teor no transcorrer do tempo das avaliações, realizadas sempre no mês de julho, mês normalmente com menor umidade relativa durante o ano. Esta diminuição do teor de água (teor médio de $14,2 \pm 0,2$ na colheita e de 7,2 $\pm 0,1 \%$ no sexto ano) foi uma condição promissora para a manutenção da viabilidade das sementes, considerando os resultados positivos obtidos por Ellis et al. (1979) na conservação de sementes de guandu por um ano, com teores iniciais de 9 e 13\%, mantidas em sacos plásticos, em condições ambientais.
Oscultivares apresentaram sementes com comportamento distinto nos resultados do teste de germinação, razão pela qual as análises estatísticas para os dois cultivares foram realizadas separadamente, para, a seguir, realizar-se a análise conjunta. Esta análise comprovou ter ocorrido interação entre cultivares e períodos de armazenamento para todos os componentes de plântulas e sementes resultantes do teste, exceto as sementes duras, que estavam presentes somente no cv. B.

A porcentagem de germinação das sementes (Figura 1A) do cv. A foi decrescendo no decorrer do período de armazenamento, porém até o terceiro ano manteve-se com germinação acima de $70 \%$, e somente do quinto para o sexto ano a queda foi drástica. Este comportamento possibilitou o ajuste da equação de terceiro grau. No cv. B, ao contrário, as sementes apresentaram aumento de germinação no início do armazenamento; entre o primeiro e o segundo ano, a tendência foi de decréscimo, com queda acentuada do terceiro para o quinto ano e diminuição gradual até o sexto ano. Uma equação de terceiro grau ajustou-se a estas médias da germinação do cv. B, mas bem distinta da obtida para o cv. A. Ambos cultivares mantiveram sementes com germinação mínima de $70 \%$ dentro dos padrões de sementes comerciais da espécie (Brasil, 2008) nos três primeiros anos de armazenamento, e com valores semelhantes aos observados para a maioria dos cultivares testados por Rao et al. (1982), quando armazenados em condições ambientais sem controle de temperatura e umidade relativa. Godoy e Souza (2004) verificaram também que o comportamento da germinação dos cultivares com e sem sementes duras foi diferente no transcorrer de quinze meses de conservação, em condições controladas de temperatura $\left(10^{\circ} \mathrm{C}\right)$ e umidade relativa $(25 \%)$.

Os resultados da porcentagem de germinação das sementes do cv. B, nas primeiras avaliações, estão relacionados à presença de sementes duras (Figura 2A), que logo após a colheita representavam $27 \%$, mas decresceram com o armazenamento, possibilitando o aumento do percentual de plântulas normais (germinação), à semelhança do ocorrido no experimento de Almeida et al. (1979). Godoy e Souza (2004) constataram em genótipos com sementes duras comportamento diferenciado quanto à presença destas durante o armazenamento por 15 meses em condições de 10 ${ }^{\circ} \mathrm{C}$ de temperatura e $25 \%$ de umidade relativa do ambiente; havendo genótipos que apresentaram decréscimos, porém após períodos distintos de armazenamento, outros que mantiveram as porcentagens constantes durante todo o período e outros ainda com aumentos das sementes duras, 
seguindo-se de decréscimo. Em função do momento de utilização dessas sementes, seria necessária a realização de escarificação das sementes face aos valores apresentados, para garantir a germinação. Para o cv. B do presente trabalho, a partir de um ano de armazenamento, a dormência da maioria das sementes foi superada, não havendo necessidade de tratamento de superação, fato que ocorreu logo após a colheita para a cv. A.
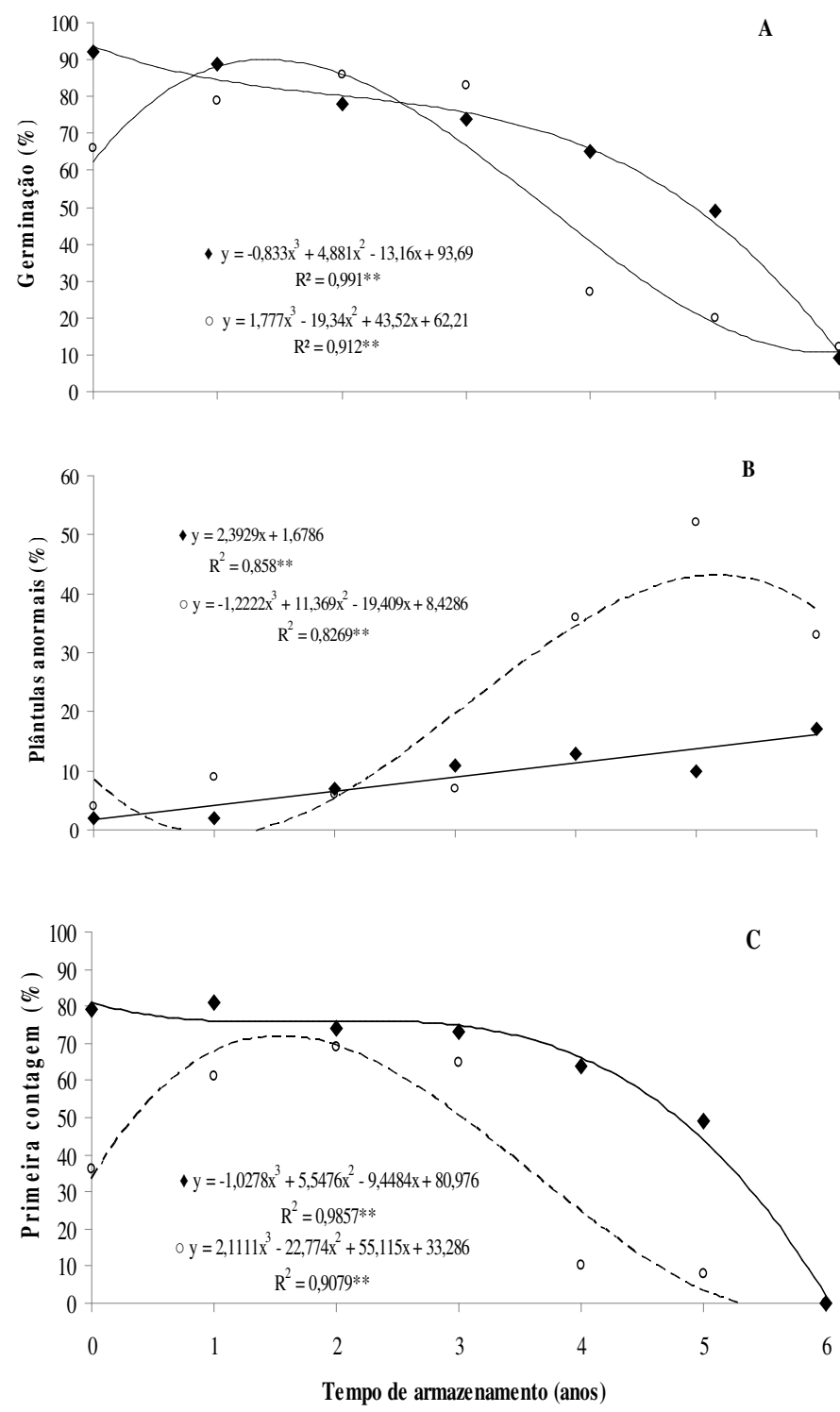

FIGURA 1. Ajustes das equações para os dados médios de germinação, plântulas anormais e germinação na primeira contagem do teste de sementes de guandu do cultivar A (४) e B ( $(\circ)$ em função do período de armazenamento.
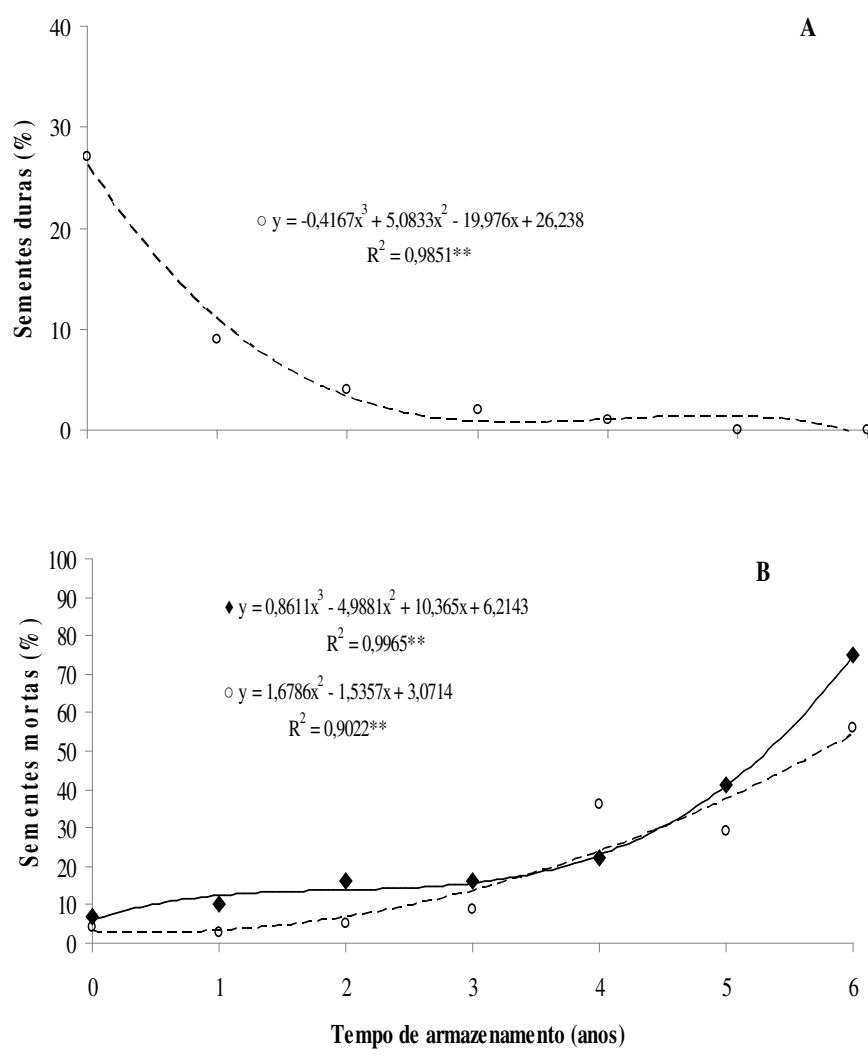

FIGURA 2. Ajustes das equações para os dados médios de sementes duras e sementes mortas do teste de germinação de sementes de guandu do cultivar A (») e B (०) em função do período de armazenamento.

No cv. A, a porcentagem de plântulas anormais (Figura 1B) foi crescente desde a avaliação inicial (logo após a colheita) até o sexto ano (último), devido à perda de vigor de número cada vez maior de sementes com o armazenamento, resultando em menor número de plântulas normais no decorrer dos anos. Acompanhando esta deterioração, de forma mais acentuada, o percentual de sementes mortas aumentou da primeira à última determinação, quando apresentou três quartos das sementes mortas (Figura 2B).

As sementes do cv. B, por apresentarem dormência, resultaram, durante os três primeiros anos de armazenamento, percentuais semelhantes tanto de plântulas anormais como de sementes mortas (Figuras 1B e $2 \mathrm{~B}$, respectivamente); seguindo-se de aumento acentuado nos valores destes a partir do quarto ano, o que justifica 
as germinações menores observadas a partir desse ano. Diferiu, portanto, do comportamento das sementes do cv. A, no qual os decréscimos de germinação decorreram da maior presença de sementes mortas, enquanto para o cv. B foi de plântulas anormais, indicando que a deterioração para essas sementes foi menor, pois maior proporção manteve-se viva, apesar de não estarem com vigor suficiente para originar plântula normal.

A primeira contagem do teste de germinação (Figura 1C) para o cv. A pode ser considerado como teste de vigor, pois retratou a perda de qualidade fisiológica das sementes com o decorrer do armazenamento, em estágio anterior de deterioração ao da germinação, pois no sexto ano acusou perda total de vigor (valor nulo) apesar de certo percentual de sementes ainda mantivessem capacidade de produzir plântulas normais (Figura 1A) e outras estivessem vivas (plântulas anormais, Figura 1B). No cv. B, a avaliação realizada logo após a colheita resultou em menor valor do que nas determinações seguintes, não devendo, por isso, considerá-las como de menor vigor, pois devido à presença de sementes duras, estas não germinaram ou atrasaram o processo. Com a perda da dormência, de forma visível a partir do segundo ano de armazenamento, este teste passou a avaliar o vigor das sementes, pois mostra a perda de qualidade devido ao envelhecimento natural das sementes a partir desse ano e, à semelhança do verificado para o cv. A, na última avaliação, o valor também foi nulo. Observou-se, portanto, a interferência das sementes duras nos resultados da primeira contagem do teste de germinação, como teste de vigor, exigindo cuidados em sua interpretação.

\section{CONCLUSÃO}

A presença de sementes duras ocasiona diferença na germinação entre cultivares de guandu no transcorrer do período de armazenamento.

\section{REFERÊNCIAS}

ALMEIDA, A.M.; NAKAGAWA, J.; DE MARCHI, M.S.; ROSOLEM, C.A. Efeitos da época de semeadura na qualidade de sementes de guandu. In: JORNADA CIENTÍFICA DA ASSOCIAÇÃO DOS DOCENTES DO CAMPUS DE BOTUCATU - UNESP, 8., Botucatu, 1979. Anais... Botucatu: Associação dos Docentes, 1979. p.9.

ASALMOL, M.N.; ZADE, V.R. Effect of seed treatment on storability of seeds of different crops. Seed Research, v.26, n.1, p.53-56, 1998.

BRASIL. Ministério da Agricultura, Pecuária e Abastecimento. Instrução Normativa $n^{\circ} 30$, de 21 de maio de 2008. Normas e padrões para produção e comercialização de sementes de espécies forrageiras de clima tropical. Diário Oficial da União, Brasília, 23/05/2008. Seção 1, p.45.

BRASIL. Ministério da Agricultura e Reforma Agrária. Secretaria Nacional de Defesa Agropecuária. Departamento Nacional de Produção Vegetal. Coordenação de Laboratório Vegetal. Regras para Análise de Sementes. Brasília, DF, 1992. 365 p.

CALEGARI, A. Leguminosas para adubação verde de verão no Paraná. Londrina: IAPAR, 1995. 118p. (Circular, 80).

ELLIS, M.A.; RAVALO, E.J.; SMITH, R.S. Methods for pigeon pea seed storage in Puerto Rico. Journal of Agriculture of University of Puerto Rico, v.63, n.4, p.423-427, 1979.

GIOMO, G.S. Efeitos de espaçamento no crescimento da planta, na produção e qualidade de sementes de guandu (Cajanus cajan (L.) Millsp), em semeadura tardia. Botucatu, 1999. 83 f. Dissertação (Mestrado em Agricultura) - Faculdade de Ciências Agronômicas, Universidade Estadual Paulista.

GODOY, R.; SOUZA, F.H.D. Dormência em sementes de guandu (Cajanus cajan (L.) Millsp). Revista Brasileira de Zootecnia, v.33, n.6, p.2201-2205, 2004 Suplemento 3 .

HEPPERLY, P.R.; RODRÍGUEZ, R. Mycofloral succession and viability losses in pigeon pea seed in Puerto Rico. Journal of Agriculture of University of Puerto Rico, v.68, n.1, p.19-31, 1984.

OTERO, J.R. Informações sobre algumas plantas forrageiras. Rio de Janeiro: Serviço de informação Agrícola. 1952. Rio de Janeiro: Serviço de Informação Agrícola. 313p. (Série Didática, 11).

PEDROSO, P.A.C.; VIEIRA, R.D.; SADER, R.; SCOTTON, L.A. Efeito de espaçamentos e densidades de plantas na produção e qualidade de sementes de guandu. Revista Brasileira de Sementes, v.10, n.2, p.45-53, 1988

RAO, N.K.; MAESEN, L.J.G.; REMANANDAN, P. Seed viability of pigeon pea stored in two environments. Netherlands Journal of Agricultural Science, v.30, p.99-103, 1982. 
SEIFFERT, N.F. Métodos de escarificação de sementes de leguminosas forrageiras tropicais. Campo Grande: Embrapa-CNPGC, 1982. 6p. (EMBRAPA-CNPGC. Comunicado Técnico, 13).
VIEIRA, R.D.; FORNASIERI FILHO, D.; NUNES, O.LG.S. Efeito da época de semeadura sobre a produção e qualidade fisiológica de sementes de guandu e labe-labe. Revista Brasileira de Sementes, v.8, n.3, p.47-54, 1986. 